\title{
Subconjunctival bevacizumab to augment trabeculectomy with mitomycin $C$ in the management of failed glaucoma surgery
}

This article was published in the following Dove Press journal:

Clinical Ophthalmology

15 September 2014

Number of times this article has been viewed

\author{
Ahmed M Saeed \\ Tarek Tawfeek AboulNasr \\ Ophthalmology Department, Benha \\ University, Egypt
}

Purpose: To provide a feasible solution to the problem of failed glaucoma surgery. The aim was to evaluate the efficacy and safety of the additional effects of a combined surgical approach. This approach augments the application of trabeculectomy with mitomycin C (MMC) by adding subconjunctival bevacizumab injection. The results were compared with those of trabeculectomy with only adjunctive MMC.

Methods: A randomized controlled prospective clinical trial included 28 eyes diagnosed with failed scarred bleb of a previous trabeculectomy. The eyes were divided into two equal groups: combined group A, "trabeculectomy with adjunctive MMC and subconjunctival bevacizumab," and control group B, "trabeculectomy with adjunctive MMC only." The main outcome results included the cumulative probability of surgical success, intraocular pressure (IOP) values, and number of IOP-lowering medications needed to achieve the target IOP.

Results: Group A achieved a cumulative probability of complete success of 0.769 and of qualified success of 0.231 at the end of the 24 month study period; group B achieved cumulative probabilities of 0.538 and 0.308 , respectively. Group A achieved a lower mean IOP value than group B, with fewer antiglaucoma drugs at all postoperative visits, but this lower value did not reach a statistically significant level $(P>0.05)$. There was no statistically significant difference between both groups regarding best corrected visual acuity, visual field parameters, operative and/or postoperative complications, and additional interventions. No significant adverse effects were caused by this combined approach.

Conclusion: Bevacizumab was not found to add much to the favorable long-term outcome of conventional trabeculectomy with MMC as a solution to the problem of scarred failed bleb.

Keywords: glaucoma, bevacizumab, mitomycin C, failed trabeculectomy, bleb failure, scarred bleb

\section{Introduction}

Trabeculectomy is the standard treatment for patients with glaucoma who have failed maximal tolerated medical therapy. Failure of the filtering bleb occurs at various times after a trabeculectomy. Scarring of the filtering bleb is caused mainly by proliferation of subconjunctival fibroblasts and the biosynthesis of collagen and other extracellular materials. ${ }^{1}$ Wound healing involves a complex interaction between humoral and cellular responses and occurs through four interconnected processes: clot formation, angiogenesis, inflammation, and collagen deposition. ${ }^{2}$

Mitomycin C (MMC) modulates wound healing by blunting the proliferative phase of fibroblast and endothelial cell growth and replication. The results are prolonged prevention of scar formation and increased likelihood of bleb survival. The effect of MMC on fibroblasts has been shown to be much more potent and durable than fluorouracil
Correspondence: Ahmed M Saeed El-Sherif Tower, 33rd El-Horreya St, El-Qanatir El-Khairiya, I362I,

Al-Qalyubiyah, Egypt

Tel +20 I 227468426

Email a-saeed775@yahoo.com 
(5-FU), requiring a single application. ${ }^{3,4}$ Because of their nonspecific effect on cell biology, application of antimetabolites can lead to cell damage, followed by bleb leakage, hypotony, corneal scarring, and endophthalmitis. ${ }^{5,6}$ Thus, alternatives are needed.

During the proliferative phase of wound healing, the process of angiogenesis results in new blood vessel formation and the subsequent release of inflammatory mediators and cytokines that lead to scar formation and bleb failure. ${ }^{7,8}$ $\mathrm{Li}$ et al found aqueous humor levels of vascular endothelial growth factor (VEGF) to be higher in glaucomatous eyes at baseline and significantly elevated after surgery. ${ }^{9}$ Tenon capsule fibroblasts demonstrated upregulation of VEGF receptor messenger RNA and protein, with resultant proliferation of fibroblast cells. Current case reports have shown evidence of reduced bleb failure after subconjunctival injections of bevacizumab as an anti-VEGF. ${ }^{10-12}$

Failed trabeculectomy was most commonly characterized by either a flattened scarred bleb or a nonfunctioning encapsulated bleb. ${ }^{13,14}$ There are several ways to manage such patients with bleb failure. Which measure is chosen has typically depended on the stage and situation of the bleb postoperatively. Once scar tissue forms at the filtering site, medical intervention without tissue scission is usually ineffective.

Although a second trabeculectomy may be necessary, it presents a surgical challenge because it may be technically difficult, of similar or even worse outcome than the first one, and with an increased risk for complications. Adjunctive antimetabolite (ie, MMC) is mandatory in these cases..$^{15}$ The application of bevacizumab at the time of surgery could temporarily block the postoperative increased VEGF concentration and its level of upregulation in the aqueous humor. ${ }^{16}$

\section{Purpose}

The purpose of this study was to provide a feasible solution to the problem of failed glaucoma surgery by evaluating the efficacy and safety of a combined surgical approach. The approach combines the additional beneficial effects of trabeculectomy with intraoperative MMC application plus subconjunctival bevacizumab injection. The results were compared with those of secondary trabeculectomy with only adjunctive MMC.

\section{Design}

This was a randomized controlled prospective clinical trial. It was carried out from July 2009 to September 2013. The postoperative evaluation and follow-up period was 24 months.

\section{Setting}

The trial was performed at the Ophthalmology Department of Benha University Hospital, Benha, Egypt.

\section{Patients and methods}

This trial included 28 eyes of 24 patients (13 women and $11 \mathrm{men}$ ) selected from those patients attending the ophthalmology clinics of Benha University Hospital.

\section{Inclusion criteria}

Patients were diagnosed with failed trabeculectomy, characterized by either a flattened scarred bleb or a nonfunctioning encapsulated bleb of a previous trabeculectomy, together with uncontrolled intraocular pressure (IOP) by maximum tolerable antiglaucoma therapy. Repeat trabeculectomy was carried out at least 8 weeks after the previous surgery and/or any maneuver applied to improve the bleb function (eg, suture lysis, needling, antimitotic injection, and so on).

\section{Exclusion criteria}

We excluded patients with neovascular glaucoma, congenital and juvenile glaucoma, other ocular pathologies (retinal surgeries, significant cataract, uveitis, corneal pathology), severe cardiovascular diseases (such as myocardial infarction, stroke, and uncontrolled systemic hypertension), unhealed wounds and collagen diseases, pregnancy and breast-feeding, or known allergy to bevacizumab, or who either missed two subsequent postoperative visits or did not complete the 24 month follow-up period or were not willing to give consent. Two patients were excluded from the study because they missed two subsequent postoperative follow-up visits.

The mean age of the 22 included patients was $59.53 \pm 7.04$ years. The 26 eyes of the 22 patients ( 12 women and 10 men) were randomly divided into two equal groups: combined group A, "trabeculectomy with adjunctive MMC and bevacizumab injection," and group B, "trabeculectomy with adjunctive MMC only." There was no statistically significant variation between the groups studied in race, sex, and age $(P>0.05)$. Informed consent was obtained from all patients after thorough explanation of the treatment approach and surgical procedures, with their possible adverse effects and potential complications, with approval of the Research Ethics Committee at the Benha faculty of Medicine, Benha University.

Baseline data included baseline IOP, recorded as the preoperative IOP, with the use of antiglaucoma drugs; ocular hypotensive medications (their class, number, duration, and 
evidence of chronic inflammation); a visual field test, using Humphrey FTD ${ }^{\circledR}$ Perimeter (Carl Zeiss Meditec, Inc, Dublin, CA, USA), using a threshold 24-2 SITA-standard program to get the baseline mean deviation (MD) and pattern standard deviation (PSD); corrected distance visual acuity (CDVA) in decimal notation; and central corneal thickness, using an ultrasonic pachymeter (Corneo-Gage plus ${ }^{\mathrm{TM}} 4 \mathrm{~s}$; Sonogage, Inc, Cleveland, OH, USA).

A complete ocular examination was performed, including anterior segment slit-lamp examination, gonioscopy using Goldmann contact lens, fundus examination (optic nerve head, vertical cup disc ratio, and nerve fiber layer if possible), and history of systemic diseases (diabetes, hypertension, collagen diseases, hepatitis, and so on). At baseline, systemic hypertension, mean glycated hemoglobin levels, hemoglobin (HB\%), and lipid profile, as well as prothrombin time and concentration, were controlled as indicated.

\section{Surgical approach}

All procedures were performed under local peribulbar anesthesia. Subconjunctival saline injection was first done at the site of the proposed flap (away from the previous failed bleb) to facilitate dissection of the adherent conjunctiva. Trabeculectomy was done through a fornix-based conjunctival flap at the selected site of loose healthy conjunctiva. A half-thickness scleral flap $(3.5 \times 3.5 \mathrm{~mm})$ was created and dissected into the clear cornea. A cellulose microsponge soaked in $0.3 \mathrm{mg} / \mathrm{mL}$ MMC solution (Mitomycin-C Kyowa ${ }^{\circledR}$; Kyowa Hakko Kogyo, Tokyo, Japan) was applied to the undersurface of the scleral flap over a wide posterior area, with the conjunctive draped over the sponge for 3 minutes. Then the sponge was removed and the entire area was lightly and copiously washed with irrigating saline. Standard trabeculectomy of equal size (two bites aside) was created by Kelly punch, peripheral iridectomy was made by scissors, and the scleral flap was closed with $10 / 0$ nylon sutures to achieve controlled seepage of the aqueous to the posterior subconjunctival space. The conjunctiva was tightly closed with 8/0 Vicryl ${ }^{\circledR}$ sutures (Vicryl ${ }^{\circledR}$ polyglactin 910; Ethicon Inc, Johnson \& Johnson, Somerville, NJ, USA). Any intraoperative complication was reported.

In group $\mathrm{B}$, at the end of the procedure, additional single subconjunctival bevacizumab (1.25 mg Avastin ${ }^{\circledR}$; Genentech, San Francisco, CA, USA) was injected by a blunt cannula passing through the tightly closed conjunctiva. It was applied near the flap edges and into the posterior conjunctival space beyond its upper edge. Postoperatively, prednisolone acetate $1 \%$ and gatifloxacin $0.3 \%$ (Optipred $^{\circledR}$ and
Tymer $^{\circledR}$; JamjoomPharma, Jeddah, Saudi Arabia) eye drops were administered five times daily for 3 weeks. Cyclopentolate $1.0 \%$ (Cicloplejico ${ }^{\circledR}$ eye drop; Alcon CUSI, S.A. EL Masnou-Barcelona, Spain) was administered three times daily for 2 weeks. Prostaglandin eye drops were stopped totally after the operation, and other antiglaucoma drugs were tailored according to IOP values for every patient at each study visit, aiming at keeping IOP at $21 \mathrm{mmHg}$ or lower with the fewest tolerable drugs.

The postoperative study visits were performed at 2 days, 1 week, and 1, 3, 6, 12, 18, and 24 months, with documentation of IOP, number of IOP-lowering drugs, BCVA, gonioscopy, fundus examination, complications, and additional maneuvers required to maintain filtration or to handle complications, as well as any additional surgical intervention. "Efficacy" was defined as postoperative IOP reduction. "Complete success" was defined as an IOP reduction of more than $20 \%$ and/or an IOP constantly lower than $21 \mathrm{mmHg}$ without any antiglaucoma medication. "Qualified success" was defined as an IOP lower than $21 \mathrm{mmHg}$ with topical antiglaucoma medication. "Failure" was defined when IOP was higher than $21 \mathrm{mmHg}$ in two subsequent follow-up visits, despite topical antiglaucoma therapy. "Complete failure" was used to describe situations in which there was a need for further glaucoma surgical interventions or when patients had no perception of light attributable to glaucoma progression. ${ }^{17}$ Colored photography of the filtering blebs was performed, and they were classified according to their morphology into the following types: type 1, a thin-walled, polycystic bleb with a transconjunctival flow of fluid that is, thus, well functioning; type 2, which is flatter, thicker, more diffuse and perilimbally extended, relatively avascular, and with good function; type 3, a flattened bleb with little or no function, in which the scarred conjunctiva firmly adheres to the underlying sclera; and type 4, an encapsulated bleb (Tenon's capsule cyst) with some engorged surface blood vessels. ${ }^{18,19}$ Perimetry was done at 12 and 24 months. Additional visits and investigations were done when required.

\section{Statistical analysis}

The program used was SPSS version 16 software (SPSS Inc., Chicago, IL, USA). Quantitative data were analyzed, using mean and standard deviation, and frequency and percentage were used with qualitative data. Student's $t$-test was used to compare means of different groups, Fisher's exact test was used to compare frequencies, and Kaplan-Meier test was used to determine survival tables. The accepted level 


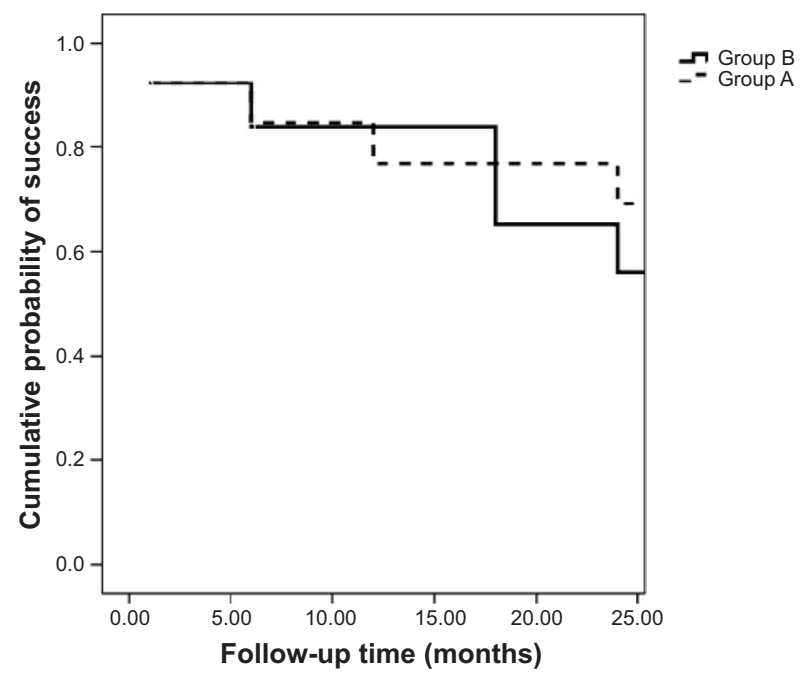

Figure I The survival curve demonstrates the surgical success of both groups during the follow-up period of 24 months.

Notes: Interrupted line represents group A (mitomycin C + bevacizumab); continuous line represents group B (mitomycin C).

of significance in this work was stated at $0.05(P<0.05$ was considered significant).

\section{Results}

The outcome data for all patients were summarized and represented according to the abovementioned definitions of success. ${ }^{17}$

\section{Survival curve and table}

The survival curve (Figure 1) demonstrated the surgical success. The survival table (Table 1) demonstrated the surgical success in both study groups analyzed at each follow-up visit of $1,6,12,18$, and 24 months postoperatively. The differences between the two groups were not statistically significant.

\section{Scatter plots}

Scatter plots illustrated the proportions of study subjects in both groups who meet the criteria for success at 12, 18, and
24 months postoperatively (Figures 2, 3, and 4, respectively), with the diagonal line at 45 degrees $(y=x)$ illustrating those with an IOP reduction after surgery (right lower half) and those of an IOP increase (left upper half) or no change.

The mean and standard deviation values of the IOP in both groups during the study period are represented in Table 2 and Figure 5.

\section{IOP and IOP-lowering drugs}

There was a statistically significant decrease in mean IOP when comparing the baseline value with the postoperative values at all postoperative points in both groups $(P<0.05)$. When comparing the two groups, the mean IOP values were always lower in combined group A than in control group B at all postoperative points, but not to a statistically significant level, as shown in Table 2 and Figure 5. In both groups, the mean number of IOP-lowering drugs was statistically significantly lower $(P<0.05)$ when comparing the baseline value with the postoperative values at any point during the follow-up period. When comparing the two groups (Figure 6), the numbers of the IOP-lowering drugs were always lower in group A at all postoperative study visits, but not to the level of statistical significance $(P=0.23,0.68$, and 0.68 , respectively).

\section{Bleb morphology}

According to the morphological classification, group A (MMC + bevacizumab) showed eight, three, and one blebs of types 1, 2, and 3, respectively, whereas group B (MMC) showed five, three, three, and two blebs of types 1, 2, 3, and 4 , respectively $(P=0.301)$.

Colored photography of the filtering blebs is represented in Figures 7-11.

\section{CDVA and VF parameters}

The baseline and the postoperative values at 24 months of CDVA and visual field parameters (MD and PSD in

Table I Surgical success and numbers in each study group analyzed at each follow-up point at I, 6, 12, I8, and 24 months postoperatively

\begin{tabular}{|c|c|c|c|c|c|c|c|c|c|c|}
\hline \multirow[t]{2}{*}{ Outcome at groups } & \multicolumn{2}{|l|}{ I month } & \multicolumn{2}{|l|}{6 months } & \multicolumn{2}{|c|}{12 months } & \multicolumn{2}{|c|}{18 months } & \multicolumn{2}{|c|}{24 months } \\
\hline & $\bar{A}$ & B & $\bar{A}$ & B & $\bar{A}$ & B & $\bar{A}$ & B & $\overline{\mathbf{A}}$ & B \\
\hline Success, N (\%) & $12(92.3)$ & II (84.6) & $12(92.3)$ & $10(76.9)$ & II (84.6) & $10(76.9)$ & II (84.6) & $8(6 \mid .5)$ & $10(76.9)$ & $7(53.8)$ \\
\hline Qualified success, N (\%) & - & - & I (7.7) & I (7.7) & $2(15.4)$ & $2(15.4)$ & I (7.7) & $3(23.1)$ & $3(23.1)$ & $4(30.8)$ \\
\hline Failure, N (\%) & I (7.7) & $2(15.4)$ & $0(0.0)$ & $2(15.4)$ & - & - & I (7.7) & I (7.7) & - & - \\
\hline Complete failure, $\mathrm{N}(\%)$ & - & - & - & - & $0(0.0)$ & I (7.7) & $0(0.0)$ & I (7.7) & $0(0.0)$ & $2(15.4)$ \\
\hline \multirow[t]{2}{*}{$P$ - and FET values } & \multicolumn{2}{|l|}{$P=0.539$} & \multicolumn{2}{|l|}{$P=0.729$} & \multicolumn{2}{|l|}{$P=1.0$} & \multicolumn{2}{|l|}{$P=0.645$} & \multicolumn{2}{|l|}{$P=0.352$} \\
\hline & \multicolumn{2}{|l|}{$\mathrm{FET}=0.377$} & \multicolumn{2}{|l|}{$\mathrm{FET}=2.047$} & \multicolumn{2}{|l|}{ FET $=1.109$} & \multicolumn{2}{|l|}{$\mathrm{FET}=2.57$} & \multicolumn{2}{|l|}{$\mathrm{FET}=2.336$} \\
\hline
\end{tabular}



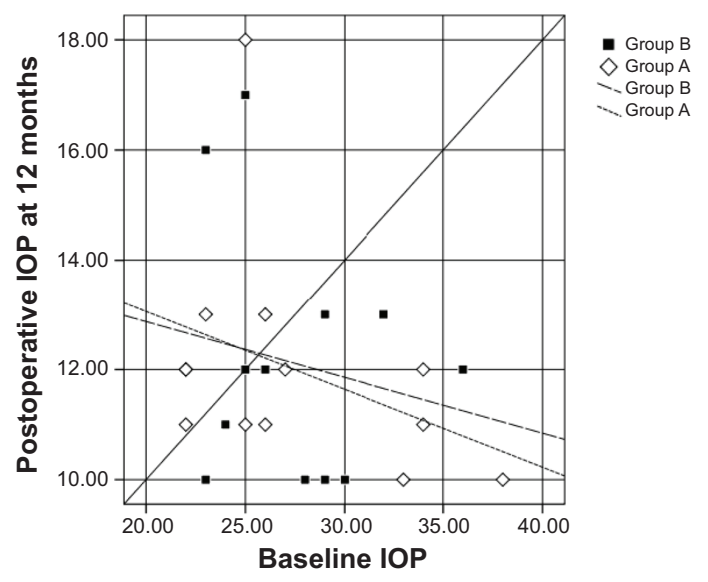

Figure 2 Scatter plots illustrating the proportions of study participants in both groups who meet the criteria for success at 12 months.

Notes: Diamonds represent group A (mitomycin C + bevacizumab); squares represent group B (mitomycin C).

Abbreviation: IOP, intraocular pressure.

decibels) in both groups were shown in Table 3. There were no statistically significant differences in the mean CDVA when comparing the preoperative with the 24 month postoperative values, neither within each group nor between both groups. One eye in each group had worse CDVA at 24 months compared with before surgery because of glaucoma progression (based on changes in Humphrey automated perimetry standard). There were no statistically significant differences in the mean MD and PSD on Humphrey automated perimetry between the two groups preoperatively and 24 months postoperatively. Two eyes in combined group A (18\%) and four eyes in control group B (30\%) demonstrated mild VF progression during the 24 month follow-up period. Group B (MMC) showed more visual field deterioration, that is, more decrease of MD and PSD values, than group A

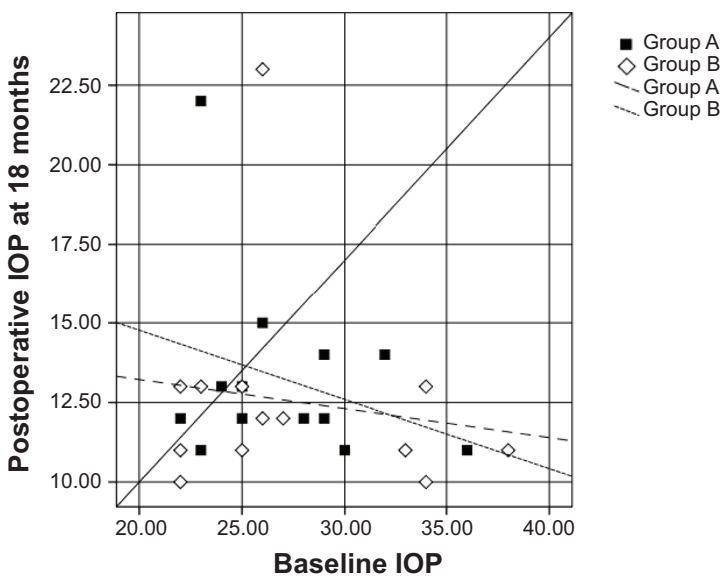

Figure 3 Scatter plots illustrating the proportions of study participants in both groups who meet the criteria for success at 18 months.

Notes: Squares represent group A (mitomycin C + bevacizumab); diamonds represent group B (mitomycin C)

Abbreviation: IOP, intraocular pressure.

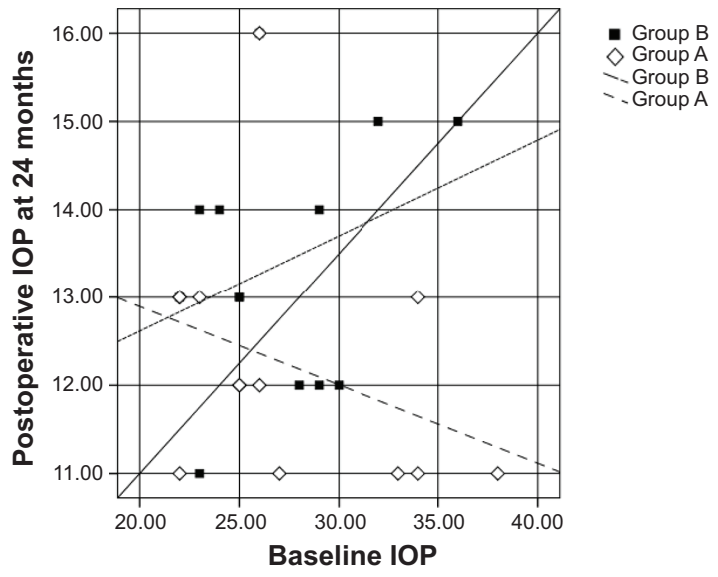

Figure 4 Scatter plots illustrating the proportions of study participants in both groups who meet the criteria for success at 24 months.

Notes: Diamonds represent group A (mitomycin C + bevacizumab); squares represent group B (mitomycin C).

Abbreviation: IOP, intraocular pressure.

(MMC + bevacizumab), but at the end of the study, that was not statistically significant.

\section{Operative complications}

The intraoperative and early and late postoperative complications of both groups are demonstrated in Table 4. The intraoperative complications were nearly equal in both groups; however, the early and late postoperative complications were less in group $\mathrm{A}$ (MMC + bevacizumab) than B (MMC), although with no statistical significance.

Additional interventions were reported as follows: suturing conjunctival wound leak (one case in each group), prophylactic intracameral and intravitreal antibiotic injection (in a case of blebitis in group B), needling of a Tenon's cyst (two in a case of group B), suture lysis (in one case in group A), and trabeculectomy revision surgery (two cases in group B at 12 and 24 months postoperatively, with no surgical complications). The needed maneuvers were significantly more marked in group B than group A.

\section{Discussion}

Trabeculectomy is the main surgical intervention for the treatment of glaucoma. Sometimes, despite initial IOP control, scarring at the site of surgery leads to loss of pressure control. ${ }^{13,14}$

Multiple factors ${ }^{20-22}$ increase the risk for trabeculectomy failure. Fibroblast migration and proliferation play a fundamental role in the obstruction of the trabeculectomy fistula, ${ }^{23}$ with greater inflammatory activity in the aqueous humor of patients who have previously undergone failed glaucoma surgery compared with those after primary glaucoma or cataract surgery. ${ }^{8}$ 
Table 2 Mean and standard deviation values of intraocular pressure in both groups during the study period

\begin{tabular}{lllllll}
\hline Variable & \multicolumn{2}{c}{ Group A } & & \multicolumn{2}{c}{ Group B } & \multicolumn{2}{c}{$\begin{array}{l}\text { Student's } \\
\text { t-test }\end{array}$} \\
\cline { 2 - 3 } & Mean & \pm Standard deviation & & Mean & \pm Standard deviation & \\
\hline IOP baseline & 27.46 & 5.43 & 27.08 & 4.07 & 0.204 & 0.84 \\
IOP, I month & 9.77 & 2.98 & 11.38 & 4.13 & 1.14 & 0.264 \\
IOP, 6 months & 11.38 & 2.79 & 13.54 & 4.39 & 1.49 & 0.148 \\
IOP, I2 months & 12.0 & 2.04 & 12.15 & 2.23 & 0.183 & 0.856 \\
IOP, I8 months & 12.54 & 3.33 & 13.23 & 2.92 & 0.563 & 0.578 \\
IOP, 24 months & 12.23 & 1.42 & 13.38 & 1.45 & 2.05 & 0.05 I \\
\hline
\end{tabular}

Abbreviation: IOP, intraocular pressure.

Trabeculectomy failure normally restarts a stepwise approach to reestablishing IOP control, beginning with medical management and, if maximum medical therapy is insufficient, proceeding until further surgical intervention becomes mandatory. Under these circumstances, we have to select from a number of surgical options, and it remains unclear as to which is the best way to manage these patients. If gonioscopy also reveals bleb failure, needling revision is not typically considered a viable option, and elective reoperation at another site or tube shunt placement is preferred. ${ }^{24}$

Conventional glaucoma filtration has limited role in a secondary trabeculectomy, so an adjuvant such as MMC is essential to prevent fibrosis and further failure of trabeculectomy. ${ }^{25}$ After surgery, the concentration of VEGF increased, and its level was upregulated in the aqueous humor; this postoperative upregulation could be blocked temporarily by the application of bevacizumab at the time of surgery. ${ }^{16}$ Anti-VEGF strongly influenced scar tissue formation during wound healing by reducing the amount of cytokines (eg, fibroblast growth factor, VEGF) released from the vessels to the site of injury by blocking angiogenesis. Bevacizumab may also indirectly render the scleral flap less adherent to its original site during the immediate postoperative period, through its direct action of fibroblast modulation. ${ }^{26}$ In addition, the wound modulator

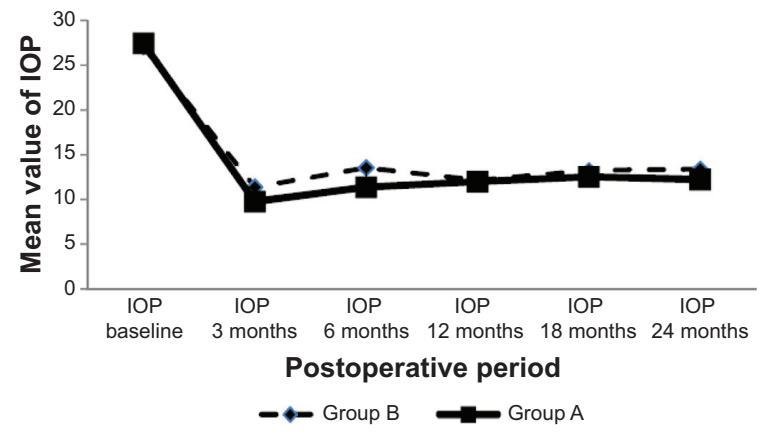

Figure 5 Mean postoperative intraocular pressure (IOP) values in both groups all during the study period.

Notes: Continuous line with squares represents group $A$ (mitomycin $C+$ bevacizumab); interrupted line with diamonds represents group B (mitomycin $C$ ). properties of anti-VEGF have revealed a dose-dependent inhibition of fibroblast proliferation, exploring their use at time of trabeculectomy, but with watertight conjunctival closure to overcome the problem of delayed wound healing. ${ }^{12}$

There are different routes of bevacizumab administration, including subconjunctival injection, intravitreal injection, and topical administration. ${ }^{27}$ Although intravitreal administration is the most effective route for intraocular tissue, the longest biologic half-life is achieved by subconjunctival injection because of bevacizumab binding to scleral matrix and its storage effect. ${ }^{28}$ With respect to filtering surgery, subconjunctival injection seems to be the most appropriate route.

The first report on the use of anti-VEGF agents as a potential wound-modulating agent was produced by Kahook et al. ${ }^{29} \mathrm{In}$ a patient with two prior failed needle revisions with MMC, the authors used $1 \mathrm{mg}$ subconjunctival bevacizumab adjacent to the bleb after needling revision. Cornish et al described the use of anti-VEGF agents as an intraoperative adjunct to primary glaucoma filtering surgery in $2009 .{ }^{30}$ They used intravitreal bevacizumab in conjunction with MMC for augmentation of high-risk trabeculectomy performed on two young diabetics. Postoperatively, they maintained functioning blebs with IOP lower than $15 \mathrm{mmHg}$ while receiving no glaucoma medications at 6 months.

The current study was supposed to have the certain advantage of adding the effect of subconjunctival bevacizumab to that of topical MMC on the wound healing process, in dealing with cases of secondary trabeculectomy as a solution to the problem of failed scarred blebs. The combined approach applied in our trial achieved a cumulative probability of complete success of 0.769 and qualified success of 1 at the end of the 24 month study period, whereas trabeculectomy with adjunctive MMC only achieved a probability of 0.538 and 0.846 , respectively. The cumulative probability of complete success was 0.923 at 1 and 6 months.

No similar studies could be found in the literature comparing the effect of combined trabeculectomy with MMC 


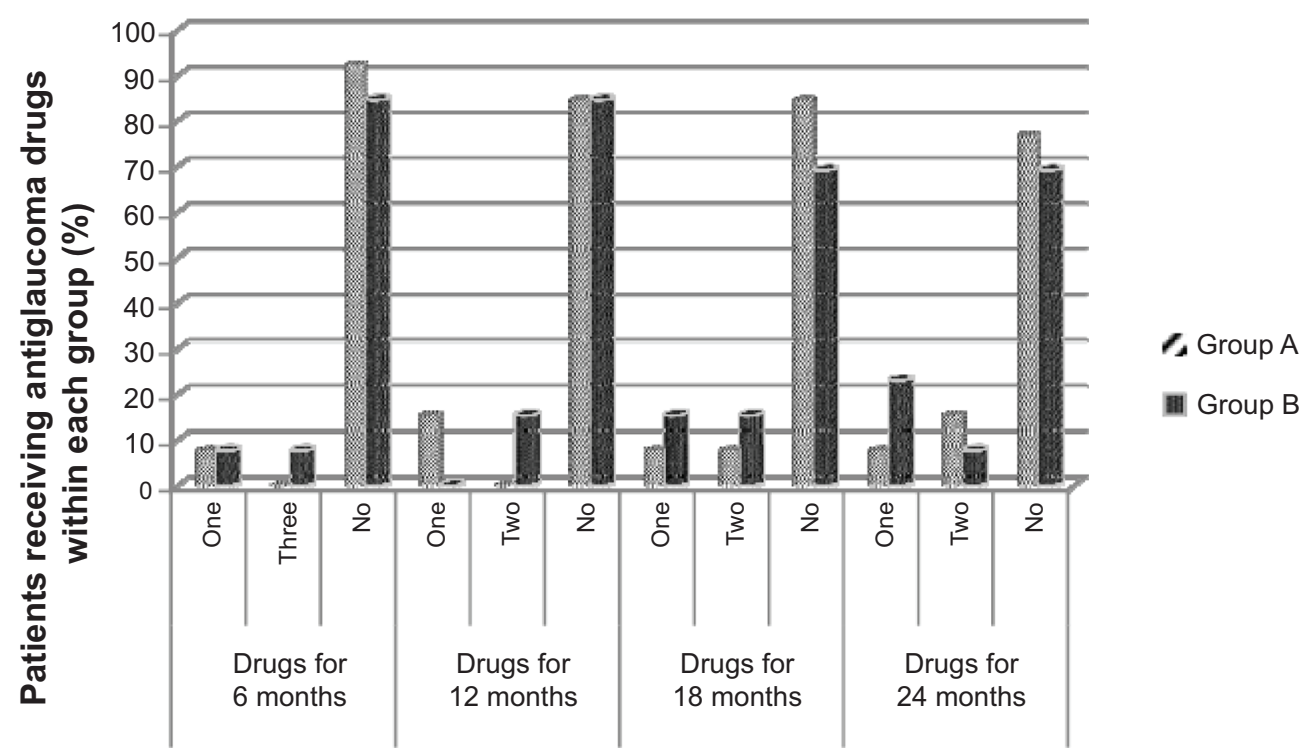

Figure 6 Percentages of patients receiving intraocular pressure-lowering drugs in both patient groups at different times of 6, I2, 18, and 24 months postoperatively. Notes: Shaded columns represent group A (mitomycin C + bevacizumab) and group B (mitomycin C).

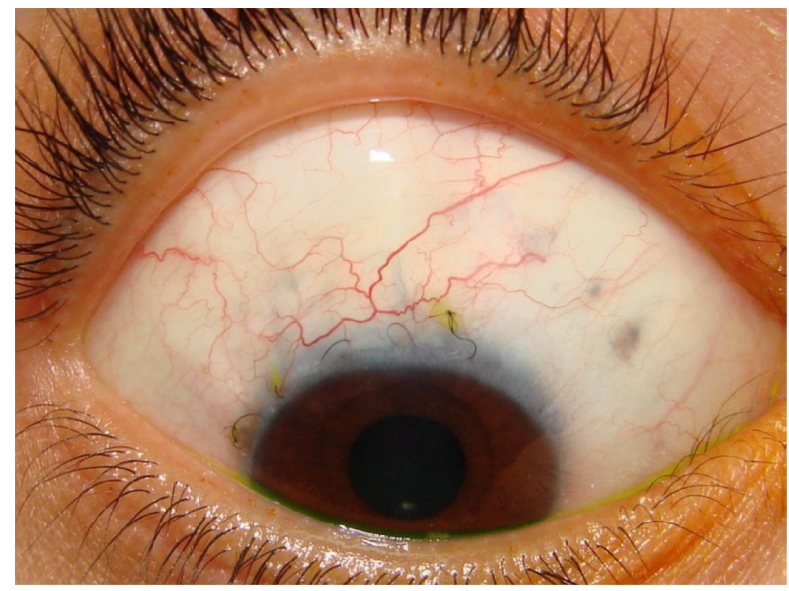

Figure 7 Functioning bleb of a group $A$ patient (mitomycin $C$ and bevacizumab) postoperatively.

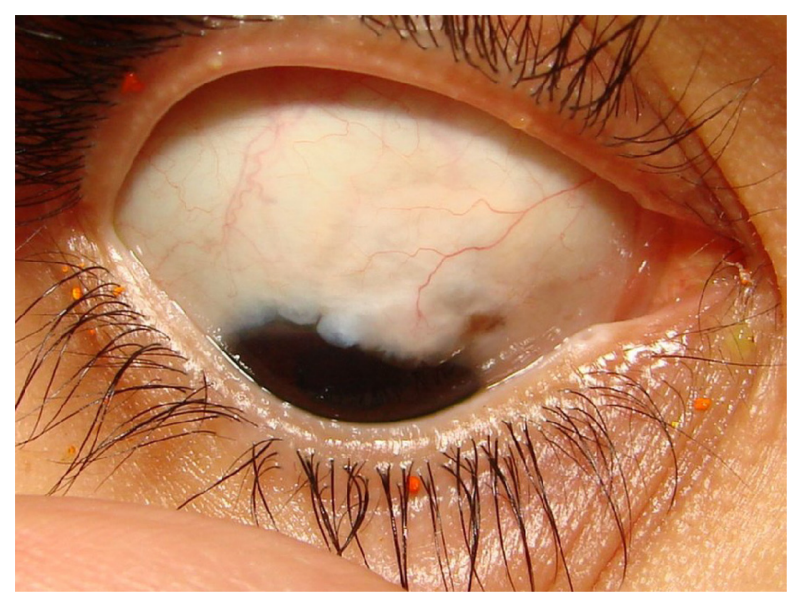

Figure 8 Functioning bleb of a group A patient (mitomycin $C$ and bevacizumab) late postoperatively.

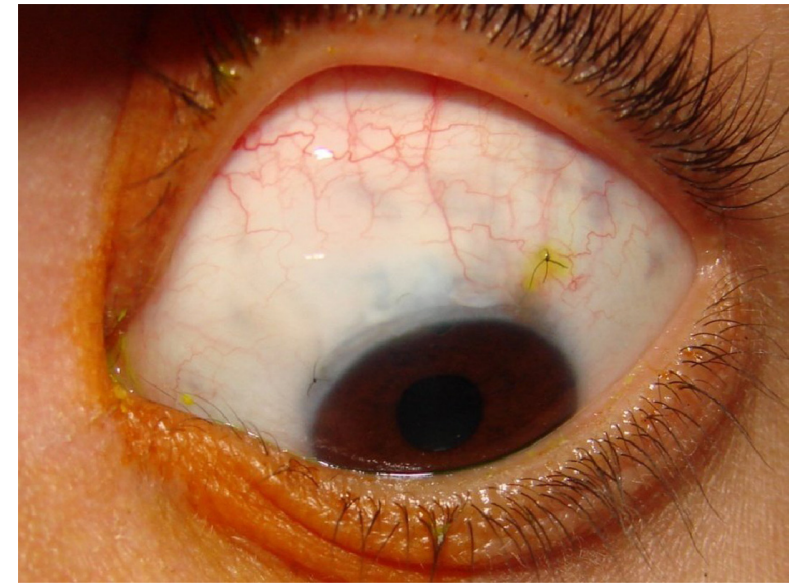

Figure 9 Functioning bleb of a group B patient (mitomycin C only) early postoperatively.

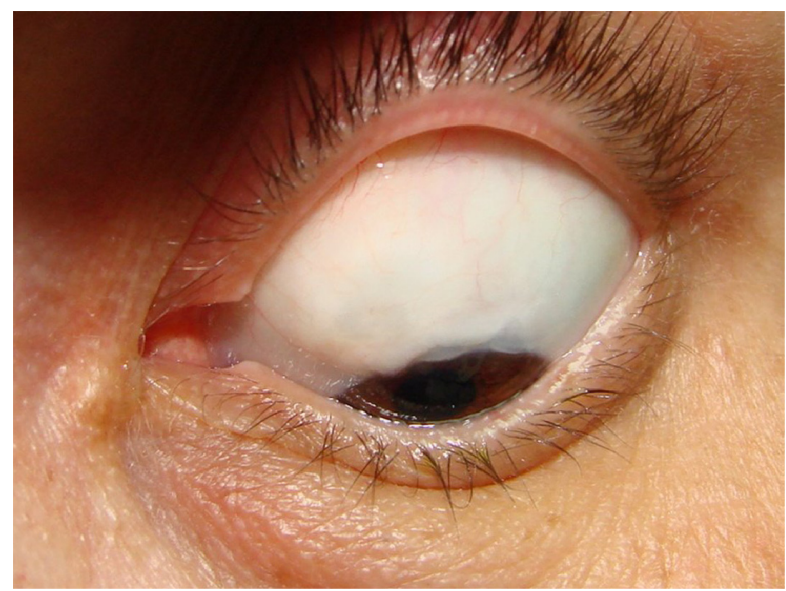

Figure 10 Functioning bleb of a group B patient (mitomycin $\mathrm{C}$ only) late postoperatively. 


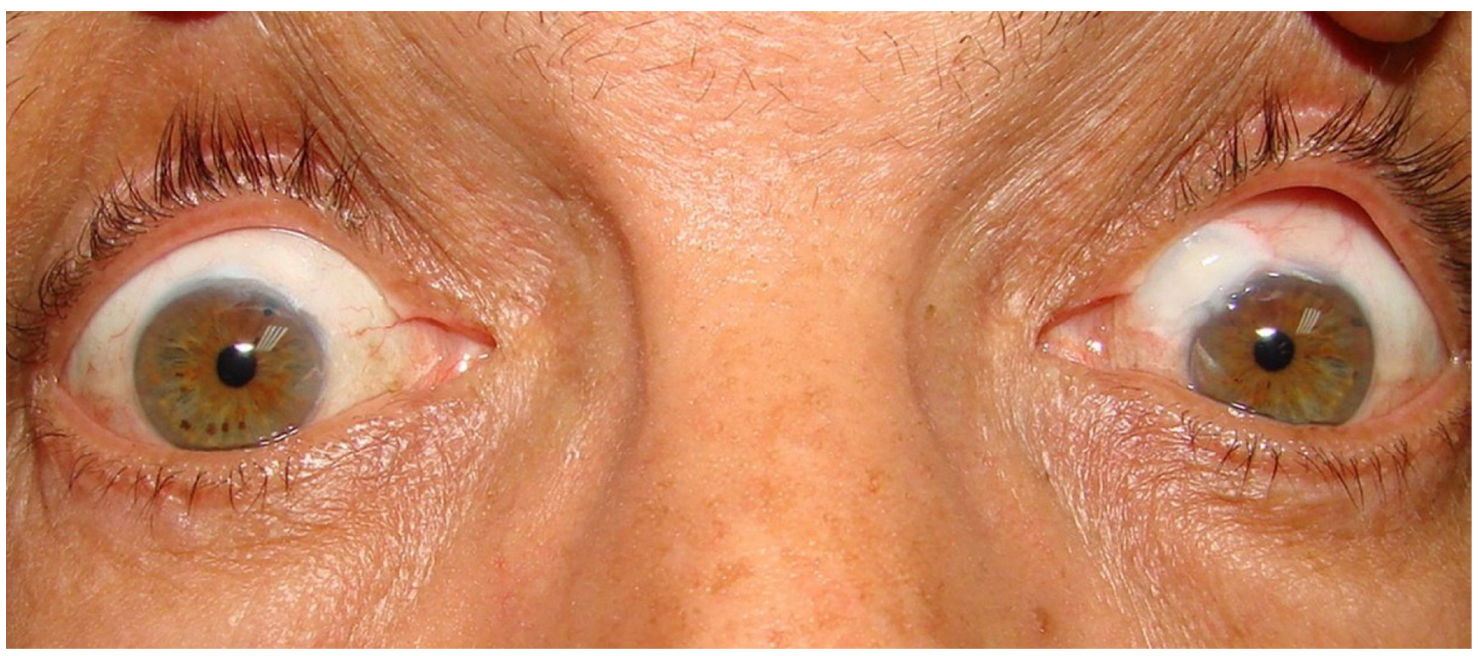

Figure I I Patient with bilateral functioning blebs. The right eye of group A (mitomycin C and bevacizumab) and the left eye of group B (mitomycin C only).

plus subconjunctival bevacizumab injection with the effect of trabeculectomy with MMC only in surgical treatment of failed scarred blebs in repeat trabeculectomy. A thorough Internet search was completed.

Nilforushan et al compared the outcome of trabeculectomy with subconjunctival bevacizumab with that of trabeculectomy with MMC in a prospective, randomized, comparative study. ${ }^{12}$ Patients with primary open-angle glaucoma (OAG) were enrolled in that trial. They reported a lessprominent effect of adjunctive subconjunctival bevacizumab with trabeculectomy than that with MMC only during a mean follow-up period of 7.8 \pm 2.2 months. Another randomized clinical trial done by Sedghipour et al examined 37 eyes of refractory OAG to assess the effect of bevacizumab in maintaining lowered IOP. ${ }^{31}$ Eyes were randomly assigned to receive bevacizumab augmentation after trabeculectomy. IOP was measured for 3 months after treatment. The authors also reported that subconjunctival bevacizumab $(0.2 \mathrm{mg})$ was not found to affect the trend in IOP more than placebo.

Sengupta et al analyzed the safety and efficacy of repeated subconjunctival bevacizumab $(1.25 \mathrm{mg} / 0.05 \mathrm{~mL})$ versus MMC $(0.03 \%)$ for preventing bleb failure in patients undergoing single-site phacotrabeculectomy for primary OAG or chronic angle-closure glaucoma. Patients were followed-up for 6 months. The subconjunctival bevacizumab group had $90 \%$ patients with complete success, as opposed to $60 \%$ in each of the other two groups $(P=0.04)$. The authors suggested that subconjunctival bevacizumab may be a useful agent for improving success after phacotrabeculectomy. ${ }^{32}$

Kahook et al compared a combined approach of intraoperative intravitreal ranibizumab along with standard trabeculectomy with $\mathrm{MMC}$ in OAG patients versus trabeculectomy with MMC only. ${ }^{33}$ The authors found no difference in IOP between the two groups. Peripheral bleb height and vascularity were significantly reduced in the ranibizumab-treated eyes; however, no adverse events were reported in either group.

In agreement with the results of the previous studies, we found that bevacizumab injection achieved better results when combined with trabeculectomy with MMC for repeat trabeculectomy, but not to the statistically significant levels. The results of this study concur with the results of other studies that also reported a limited beneficial role of bevacizumab in conjunction with trabeculectomy when compared with MMC. ${ }^{31-33}$

Table 3 Baseline and the postoperative values at 24 months of corrected distance visual acuity and visual field parameters (mean deviation and pattern standard deviation in decibels) in both groups

\begin{tabular}{|c|c|c|c|c|c|c|}
\hline \multirow[t]{2}{*}{ Variable } & \multicolumn{2}{|r|}{ Group A } & \multicolumn{2}{|r|}{ Group B } & \multirow{2}{*}{$\begin{array}{l}\text { Student's } \\
\text { t-test }\end{array}$} & \multirow[t]{2}{*}{$P$-value } \\
\hline & Mean & \pm Standard deviation & Mean & \pm Standard deviation & & \\
\hline Corrected distance visual acuity, baseline & 0.569 & 0.293 & 0.585 & 0.313 & 0.129 & 0.898 \\
\hline Corrected distance visual acuity, 24 months & 0.585 & 0.254 & 0.515 & 0.313 & 0.619 & 0.542 \\
\hline Mean deviation, baseline & 15.15 & 3.58 & 13.38 & 2.53 & 1.46 & 0.159 \\
\hline Mean deviation, 24 months & 16.23 & 4.27 & 15.69 & 3.82 & 0.339 & 0.737 \\
\hline Pattern standard deviation, baseline & 5.31 & 2.06 & 4.85 & 1.77 & 0.613 & 0.546 \\
\hline Pattern standard deviation, 24 months & 5.15 & 3.02 & 6.62 & 2.43 & 1.36 & 0.187 \\
\hline
\end{tabular}


Table 4 The intraoperative and early and late postoperative complications of both groups

\begin{tabular}{|c|c|c|c|c|}
\hline & $\begin{array}{l}\text { Group A, N (\%) } \\
(n=13)\end{array}$ & $\begin{array}{l}\text { Group B, N (\%) } \\
(n=13)\end{array}$ & FET & $P$-value \\
\hline Intraoperative complications & & & 3.06 & 0.801 \\
\hline Conjunctival buttonhole & I (7.7) & I (7.7) & & \\
\hline Scleral flap problems & I (7.7) & $0(0.0)$ & & \\
\hline Iris prolapse & I (7.7) & I (7.7) & & \\
\hline AC bleeding & $0(0.0)$ & I (7.7) & & \\
\hline Vitreous prolapse & I (7.7) & I (7.7) & & \\
\hline Intrableb bleeding & I (7.7) & $0(0.0)$ & & \\
\hline \multicolumn{5}{|c|}{ Early postoperative complications (within I month) } \\
\hline Hypotony & I (7.7) & I (7.7) & 10.12 & 0.182 \\
\hline Surgically induced astigmatism & I (7.7) & $2(15.4)$ & & \\
\hline Peripheral loss of the AC & $0(0.0)$ & I (7.7) & & \\
\hline Serous choroidal detachment & I (7.7) & I (7.7) & & \\
\hline Macular edema & $0(0.0)$ & $2(15.4)$ & & \\
\hline Hyphema & $0(0.0)$ & $2(I 5.4)$ & & \\
\hline Corneal edema & I (7.7) & $2(15.4)$ & & \\
\hline \multicolumn{5}{|l|}{ Late postoperative complications } \\
\hline Bleb leak & $0(0.0)$ & I (7.7) & 6.47 & 0.263 \\
\hline Ischemic avascular cystic bleb & $3(23.1)$ & $3(23.1)$ & & \\
\hline Blebitis & $0(0.0)$ & I (7.7) & & \\
\hline High bleb with dellen & $2(15.4)$ & $3(23.1)$ & & \\
\hline Tenon's cyst & $0(0.0)$ & $2(15.4)$ & & \\
\hline
\end{tabular}

Abbreviations: FET, Fisher's exact test; AC, anterior chamber.

In contrast, this combined approach achieved higher success when compared with other studies reporting on failed glaucoma surgery. Lankaranian et al had implanted the Ex-Press ${ }^{\mathrm{TM}}$ miniature glaucoma implant (R-50 and T-50; Alcon, Fort Worth, TX, USA) in 100 patients with previous failed glaucoma or cataract surgeries with a mean follow-up period of $27 \pm 13.2$ months. ${ }^{34}$ Coupin et al also showed comparable results at 12 months, with an overall success rate of $87 \%$ and a complete success rate of $63 \%$. It should be noted that the baseline IOP in their study $(22.9 \mathrm{mmHg})$ was less than in ours $(27.46 \pm 5.43 \mathrm{mmHg}){ }^{35}$

The combined approach used achieved a statistically significant decrease in mean IOP when comparing the baseline value with the postoperative values at all postoperative points ( $P$ was always $<0.05$ ). This should be considered in relation to the mean numbers of the given IOP-lowering drugs, where there was also a statistically significant decrease in the mean number of IOP-lowering drugs when comparing the baseline value with the postoperative values at all postoperative points ( $P$ was always $<0.05$ ). When compared with the values of the trabeculectomy with adjunctive MMC only, it was also possible to achieve lower mean IOP values with fewer antiglaucoma drugs at all postoperative visits $(P>0.05)$.

When comparing the results of our combined approach with those reported by Lankaranian et al a lower mean IOP could be achieved $(12.23 \pm 1.42$ and $14.02 \pm 5.1 \mathrm{mmHg}$, respectively). ${ }^{34}$
Olali et a ${ }^{15}$ used the same technique of trabeculectomy with MMC application. They reported a comparable result ( $54 \%$ success rate) to that of our control group, which is much less than our combined approach (77\%). Law et al had complete success rates of repeat trabeculectomy with MMC of $29 \%$ at 3 years. Their result was significantly poorer than the result of our similar group A $(54 \%) .{ }^{36}$ Differences in results may relate to their use of both fornix- and limbal-based procedures (as opposed to only fornix-based surgery in our series), less aggressive postoperative bleb manipulation, and different patients' inclusion criteria.

Cha et al also compared the outcomes for the 18 patients in their repeat trabeculectomy group. ${ }^{37}$ They achieved unqualified and qualified success rates of $50 \%$ and $90 \%$ after a mean follow-up of 36.7 months, while using the same definition of success. The results were similar to our MMC-only group series. Yun and Cha also presented a retrospective review of 44 eyes after repeat trabeculectomy with MMC..$^{38}$ Their cumulative success rate, defined as IOP of $21 \mathrm{mmHg}$ or lower, regardless of additional glaucoma medications, was achieved in $89.6 \%$ of the participants after 12 months, which is very similar to the $85 \%$ in our control group $\mathrm{B}$, using the same definition of success at the same point.

The tube versus trabeculectomy (TVT) study has suggested that IOP control with tube surgery is superior to that achieved with trabeculectomy with MMC $(0.5 \mathrm{mg} / \mathrm{mL})$ in patients who have had previous trabeculectomy. ${ }^{39,40}$ Complete 
success rates at 3 years in patients who had a previous trabeculectomy were $71 \%$ in the tube group and $64 \%$ in the trabeculectomy group. TVT results were comparable with $77 \%$ in our combined approach and $54 \%$ in our control group at 2 years. The success rate achieved by the combined approach applied in our current work exceeds the previous results at 2 years, using the same definition of success. It is worth mentioning that the TVT cohort did make up $40 \%$ of patients of African descent who have increased risk for trabeculectomy failure. Although glaucoma drainage implants offer a good surgical option in cases of failed glaucoma surgery and can provide a comparable cumulative success to our combined approach, they had many drawbacks and disadvantages, such as difficult positioning of the plate because of the presence of tightly adherent conjunctiva, limitation of free full-range ocular movement, tube obstruction, tubecornea touch, tube exposure, increased liability for hypotony, shallow anterior chamber (AC), postoperative endophthalmitis, increased requirements for penetrating keratoplasty, and subsequent cataract extraction. ${ }^{41}$ Finally, another kind of surgery used after failed trabeculectomy as a supraciliary shunt implant showed a high rate of failure ${ }^{42}$ because of fibroblast invasion of the shunt. ${ }^{43,44}$

In agreement with You et al we have demonstrated that MMC application under both the conjunctiva and scleral flaps improves IOP outcomes. ${ }^{45}$ It can be seen from this study that use of lower doses of MMC only under the flap titrated against risk and supplemented by postoperative topical application will achieve better IOP control with less marked complications.

The morphological classification of the blebs showed that $91.7 \%$ versus $61.5 \%$ of the blebs were functioning (type 1 and 2) in the combined approach compared with the control. This could be because of the additional beneficial effect of the injected anti-VEGF, as it interferes with fibroblast and tissue proliferation. ${ }^{12}$

There was no statistically significant difference between both groups regarding CDVA and VF parameters. There was no reduction in the mean VA during follow-up after surgery, and no patients progressed to lose light perception. One patient in each group lost two Snellen lines at final follow-up for various reasons. Some of the visual loss may be attributed partly or entirely to the surgery (cataract and corneal edema), and in other cases, it was related to comorbidity (diabetic retinopathy and age-related macular degeneration). When compared with the TVT study, higher rates of visual loss have been reported in both tube and trabeculectomy groups, ${ }^{39,40}$ and a reduction in mean visual acuity was mainly a result of cataract in both primary and repeat trabeculectomies. ${ }^{36} \mathrm{We}$ used MD and PSD for studying VF progression in this study. There were no statistically significant changes of these parameters, corroborating that there was little further visual loss related to glaucoma progression during the follow-up period. The results of this trial may be considered sufficient to prevent any further glaucoma-related visual loss.

The early and late postoperative complications were less in the combined approach when compared with group B. Despite their use of an AC maintainer and releasable sutures, Olali et al reported more complications in comparison with our results. ${ }^{15}$ These authors had six eyes (12\%) develop postoperative hypotony, and three of them developed persistent hypotony that required bleb revision. Two patients developed significant hyphema, requiring intracameral tissue plasminogen activator. All our operative complications were mild and could be managed safely without adding more risk or significant long-term effect to the patients. All additional interventions passed safely with no further complications.

\section{Conclusion}

Bevacizumab was not found to add much to the favorable long-term outcome of conventional trabeculectomy with MMC as a solution to the problem of scarred failed bleb. Subconjunctival bevacizumab injection achieved better results when combined with trabeculectomy with MMC for repeat trabeculectomy, but not to statistically significant levels.

\section{Disclosure}

The authors report no conflicts of interest in this work.

\section{References}

1. Skuta GL, Beeson CC, Higginbotham EJ, et al. Intraoperative mitomycin versus postoperative 5-fluorouracil in high-risk glaucoma filtering surgery. Ophthalmology. 1992;99(3):438-444.

2. Daneshvar R. Anti-VEGF Agents and Glaucoma Filtering Surgery. J Ophthalmic Vis Res. 2013;8(2):182-186.

3. Jampel HD. Effect of brief exposure to mitomycin C on viability and proliferation of cultured human Tenon's capsule fibroblasts. Ophthalmology. 1992;99(9):1471-1476.

4. Smith S, D'Amore PA, Dreyer EB. Comparative toxicity of mitomycin C and 5-fluorouracil in vitro. Am J Ophthalmol. 1994;118(3): 332-337.

5. Greenfield DS, Suñer IJ, Miller MP, Kangas TA, Palmberg PF, Flynn HW Jr. Endophthalmitis after filtering surgery with mitomycin. Arch Ophthalmol. 1996;114(8):943-949.

6. Seah SK, Prata JA Jr, Minckler DS, Baerveldt G, Lee PP, Heuer DK. Hypotony following trabeculectomy. J Glaucoma. 1995;4(2):73-79.

7. Chang MR, Cheng Q, Lee DA. Basic science and clinical aspects of wound healing in glaucoma filtering surgery. J Ocul Pharmacol Ther. 1998;14(1):75-95.

8. Skuta GL, Parrish RK II. Wound healing in glaucoma filtering surgery. Surv Ophthalmol. 1987;32(3):149-170. 
9. Li Z, Van Bergen T, Van de Veire S, et al. Inhibition of vascular endothelial growth factor reduces scar formation after glaucoma filtration surgery. Invest Ophthalmol Vis Sci. 2009;50(11): 5217-5225.

10. Kahook MY, Schuman JS, Noecker RJ. Intravitreal bevacizumab in a patient with neovascular glaucoma. Ophthalmic Surg Lasers Imaging. 2006;37(2):144-146.

11. Grewal DS, Jain R, Kumar H, Grewal SP. Evaluation of subconjunctival bevacizumab as an adjunct to trabeculectomy a pilot study. Ophthalmology. 2008;115(12):2141-2145.e2.

12. Nilforushan N, Yadgari M, Kish SK, Nassiri N. Subconjunctival bevacizumab versus mitomycin $\mathrm{C}$ adjunctive to trabeculectomy. Am J Ophthalmol. 2012;153(2):352-357.e1.

13. Agarwal HC, Sharma TK, Sihota R, Gulati V. Cumulative effect of risk factors on short-term surgical success of mitomycin augmented trabeculectomy. J Postgrad Med. 2002;48(2):92-96.

14. Broadway DC, Chang LP. Trabeculectomy, risk factors for failure and the preoperative state of the conjunctiva. J Glaucoma. 2001;10(3): 237-249.

15. Olali C, Rotchford AP, King AJ. Outcome of repeat trabeculectomies. Clin Experiment Ophthalmol. 2011;39(7):658-664.

16. Jonas JB, Spandau UH, Schlichtenbrede F. Intravitreal bevacizumab for filtering surgery. Ophthalmic Res. 2007;39(2):121-122.

17. Shaarawy MT, Sherwood MB, Grehn F. Guidelines on Design and Reporting of Glaucoma Surgical Trials. Amsterdam: Kugler Publications; 2009:15-24.

18. Kronfeld PC. The mechanisms of filtering operations. Trans Pac Coast Otoophthalmol Soc Annu Meet. 1949;33:23-40.

19. Van Buskirk EM. Cysts of Tenon's capsule following filtration surgery. Am J Ophthalmol. 1982;94(4):522-527.

20. Broadway D, Grierson I, Hitchings R. Racial differences in the results of glaucoma filtration surgery: are racial differences in the conjunctival cell profile important? Br J Ophthalmol. 1994;78(6):466-475.

21. Broadway DC, Grierson I, O'Brien C, Hitchings RA. Adverse effects of topical antiglaucoma medication. II. The outcome of filtration surgery. Arch Ophthalmol. 1994;112(11):1446-1454.

22. Mietz H, Raschka B, Krieglstein GK. Risk factors for failures of trabeculectomies performed without antimetabolites. Br J Ophthalmol. 1999;83(7):814-821.

23. Joseph JP, Grierson I, Hitchings RA. Chemotactic activity of aqueous humor. A cause of failure of trabeculectomies? Arch Ophthalmol. 1989; 107(1):69-74.

24. Paris G, Zhao M, Sponsel WE. Operative revision of non-functioning filtering blebs with 5-fluorouracil to regain intraocular pressure control. Clin Experiment Ophthalmol. 2004;32(4):378-382.

25. Singh K, Mehta K, Shaikh NM, et al. Trabeculectomy with intraoperative mitomycin C versus 5-fluorouracil. Prospective randomized clinical trial. Ophthalmology. 2000;107(12):2305-2309.

26. Budenz DL, Taba KE, Feuer WJ, et al. Surgical management of secondary glaucoma after pars plana vitrectomy and silicone oil injection for complex retinal detachment. Ophthalmology. 2001;108(9): 1628-1632.

27. Żarnowski T, Tulidowicz-Bielak M. Topical bevacizumab is efficacious in the early bleb failure after trabeculectomy. Acta Ophthalmol (Copenh). 2011;89(7):e605-e606.

28. Nomoto H, Shiraga F, Kuno N, et al. Pharmacokinetics of bevacizumab after topical, subconjunctival, and intravitreal administration in rabbits. Invest Ophthalmol Vis Sci. 2009;50(10):4807-4813.

Clinical Ophthalmology

\section{Publish your work in this journal}

Clinical Ophthalmology is an international, peer-reviewed journal covering all subspecialties within ophthalmology. Key topics include: Optometry; Visual science; Pharmacology and drug therapy in eye diseases; Basic Sciences; Primary and Secondary eye care; Patient Safety and Quality of Care Improvements. This journal is indexed on Submit your manuscript here: http://www.dovepress.com/clinical-ophthalmology-journal
29. Kahook MY, Schuman JS, Noecker RJ. Needle bleb revision of encapsulated filtering bleb with bevacizumab. Ophthalmic Surg Lasers Imaging. 2006;37(2):148-150.

30. Cornish KS, Ramamurthi S, Saidkasimova S, Ramaesh K. Intravitreal bevacizumab and augmented trabeculectomy for neovascular glaucoma in young diabetic patients. Eye (Lond). 2009;23(4):979-981.

31. Sedghipour MR, Mostafaei A, Taghavi Y. Low-dose subconjunctival bevacizumab to augment trabeculectomy for glaucoma. Clin Ophthalmol. 2011;5:797-800.

32. Sengupta S, Venkatesh R, Ravindran RD. Safety and efficacy of using off-label bevacizumab versus mitomycin $\mathrm{C}$ to prevent bleb failure in a single-site phacotrabeculectomy by a randomized controlled clinical trial. J Glaucoma. 2012;21(7):450-459.

33. Kahook MY. Bleb morphology and vascularity after trabeculectomy with intravitreal ranibizumab: a pilot study. Am J Ophthalmol. 2010; 150(3):399-403.e1.

34. Lankaranian D, Razeghinejad MR, Prasad A, et al. Intermediate-term results of the Ex-PRESS miniature glaucoma implant under a scleral flap in previously operated eyes. Clin Experiment Ophthalmol. 2011;39(5): 421-428.

35. Coupin A, Li Q, Riss I. Implant miniature Ex-PRESS placé sous un volet scléral dans la chirurgie du glaucome à angle ouvert: étude rétrospective. [Ex-PRESS miniature glaucoma implant inserted under a scleral flap in open-angle glaucoma surgery: a retrospective study]. J Fr Ophtalmol. 2007;30(1):18-23. French.

36. Law SK, Shih K, Tran DH, Coleman AL, Caprioli J. Long-term outcomes of repeat vs initial trabeculectomy in open-angle glaucoma. $\mathrm{Am}$ J Ophthalmol. 2009;148(5):685-695.e1.

37. Cha S, Son J, Chang J, Chung W. Comparison of surgical outcomes in primary trabeculectomy with mitomycin $\mathrm{C}$ versus repeat trabeculectomy with mitomycin C. Invest Ophthalmol Vis Sci. 2004;45:SS94-B878.

38. Yun Y, Cha S. Outcomes of repeat trabeculectomy with mitomycin C for previous failed trabeculectomy. J Korean Ophthalmol Soc. 2005;46: 297-305. Korean.

39. Gedde SJ, Schiffman JC, Feuer WJ, Herndon LW, Brandt JD, Budenz DL. Treatment outcomes in the tube versus trabeculectomy study after one year of follow-up. Am J Ophthalmol. 2007;143(1):9-22.

40. Gedde SJ, Schiffman JC, Feuer WJ, Herndon LW, Brandt JD, Budenz DL; Tube Versus Trabeculectomy Study Group. Three-year follow-up of the tube versus trabeculectomy study. Am J Ophthalmol. 2009;148(5): 670-684.

41. Al-Aswad LA, Netland PA, Bellows AR, et al. Clinical experience with the double-plate Ahmed glaucoma valve. Am J Ophthalmol. 2006; 141(2):390-391.

42. Mastropasqua L, Agnifili L, Ciancaglini M, et al. In vivo analysis of conjunctiva in gold micro shunt implantation for glaucoma. $\mathrm{Br} J$ Ophthalmol. 2010;94(12):1592-1596.

43. Agnifili L, Costagliola C, Figus M, et al. Histological findings of failed gold micro shunts in primary open-angle glaucoma. Graefes Arch Clin Exp Ophthalmol. 2012;250(1):143-149.

44. Rękas M, Pawlik B, Grala B, Kozłowski W. Clinical and morphological evaluation of gold micro shunt after unsuccessful surgical treatment of patients with primary open-angle glaucoma. Eye (Lond). 2013;27(10): 1214-1217.

45. You YA, Gu YS, Fang CT, Ma XQ. Long-term effects of simultaneous subconjunctival and subscleral mitomycin $\mathrm{C}$ application in repeat trabeculectomy. J Glaucoma. 2002;11(2):110-118.

\section{Dovepress}

PubMed Central and CAS, and is the official journal of The Society of Clinical Ophthalmology (SCO). The manuscript management system is completely online and includes a very quick and fair peer-review system, which is all easy to use. Visit http://www.dovepress.com/ testimonials.php to read real quotes from published authors. 